\title{
Review Paper: Factors Influencing the Hearing Aids Use and Satisfaction: A Review Study
}

\author{
Mahsa Hamidi Pouyandeh¹ ${ }^{1}$, Reza Hoseinabadi ${ }^{*}$ (iD \\ 1. Department of Audiology, School of Rehabilitation, Tehran University of Medical Sciences, Tehran, Iran.
}

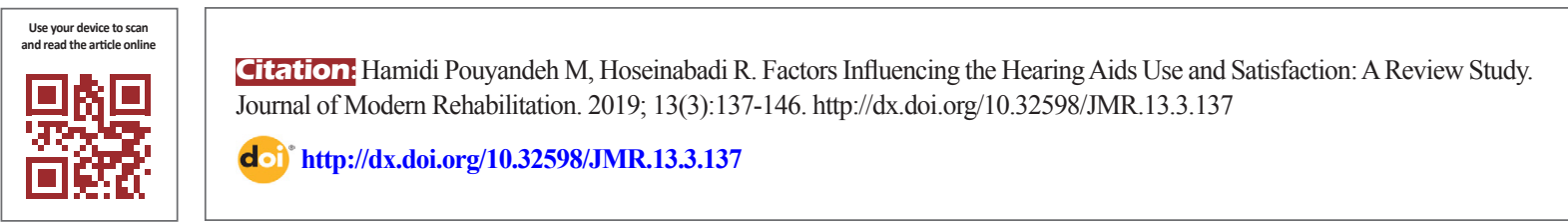

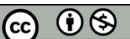

Article info:

Received: 02 Feb 2019

Accepted: 25 May 2019

Available Online: 01 Jul 2019

\section{Keywords:}

Hearing loss, Hearing ais, Assistive listening devices

\begin{abstract}
Introduction: Hearing loss is a common problem that may end in disability and handicap. The primary treatment of hearing loss is using hearing aids. However, many patients, despite being aware of this problem, are not interested in using these devices. Some factors affect the process of receiving and using hearing aids, some of which are related to the person's characteristics. In this article, we will investigate the possible factors and their roles in using hearing aids by the patients.

Materials and Methods: We searched Google Scholar, PubMed and ScienceDirect database over the last twenty years, with the keywords of "hearing aid", "use", "satisfaction", and "benefit". The result of this search was 399 articles, out of which 77 articles were related to this topic.

Discussion: Different factors affecting the usefulness of hearing aids can be investigated in two stages. The first is the stage before receiving hearing aids when a person looks for help and receives hearing aid, and the second stage after receiving the hearing aid when the person has used the hearing aid and reports his or her satisfaction. The factors affecting the receiving stage are the amount of hearing loss, problems experienced by the person, the patient's motives and expectations, personality traits, auditory counseling, and economic issues. However, after receiving a hearing aid, factors such as other non-auditory abilities, hearing loss, age, duration of hearing aid use, hearing aids characteristics, disabilities, attitudes, and personality traits affect the satisfaction of the patient.
\end{abstract}

\section{Introduction}

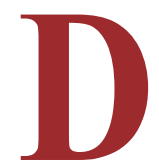

espite the high prevalence of hearing impairments, few people use hearing aids. In other words, a small proportion of adults with hearing impairment are seeking to resolve their hearing problems with using hearing aids. Several studies report that many people who can benefit from hearing aids do not use it [1-3]. Besides, those with hearing aids either do not regularly use it or are not satisfied with it [2]. Studies conducted in the UK, Finland, Denmark, Australia, and the United States report that $1 \%-40 \%$ of prescribed hearing aids are either never used or infrequently used [2, 4-6]. Some factors are responsible for abandoning hearing aids by people with hearing impairments. We can mention some 
factors, such as the denial of hearing loss, stigma, and financial issues. The principle barriers are the people's unique perspective about hearing loss when they believe that it is not such a problem to be resolved by hearing aids [7].

The various stages that a person with hearing impairment should walk through in the process of receiving a hearing aid include before the hearing aid use, during hearing aid fitting, and after receiving it. In each stage, some factors affect the use of hearing aids, including feelings and views (motivation, expectations, and attitudes), personal characteristics (age, gender), and external factors (cost, counseling). Of these factors, only the reported disabilities from the person can have a positive effect on all the variables assessed in the examination of the application of the hearing aid [8].

For a long time, several measures have been used to examine the usefulness of hearing aids: performance, benefits, satisfaction, and time of hearing aids use $[4,9,10]$. The hearing aid's benefit can be defined as an increase in hearing ability after its use. In the objective assessments of benefits, the patient's opinion or judgment on hearing aids use is not necessary. There are many evaluations for verifying and checking the benefits of hearing aids. These include objective speech recognition [11] and acoustic evaluations of hearing aids in the coupler or real ear $[12,13]$. Subjective benefit evaluations are performed using a grading criterion, for example, in terms of loudness or sound quality, that needs the patient's judgment $[14,15]$. Subjective measures are also evaluated in terms of reduction in disability or handicap that the patient feels [16].

Based on the World Health Organization definition, disability is a functional consequence of disorder, and handicap is its psychosocial consequence [17]. Several questionnaires, such as the Profile of Hearing Aid Benefit (PHAB) [18] and Hearing Handicap Inventory For elderly (HHIE) [19], have been developed to assess the degree of disability and handicap. Humes [20] introduced the usefulness of the hearing aid, including the recognition of speech recognition and HHIE, the length of use of hearing aids, the relative level of loudness and sound quality, and satisfaction. Satisfaction is an internal feeling that can be evaluated either as an overall assessment or separately in each section.

Although total satisfaction with hearing aids depends on its benefits, satisfaction and benefits are two distinct dimensions of the success of hearing aid use. The psychosocial effects of hearing aids have also been studied.
Muller et al. reported improved cognitive function and reduced depression in patients who received hearing aids compare to those without hearing aids [21]. Satisfaction with life has also been seen in successful users of hearing aids [22]. In hearing aid users, the lower tendency to depression [23] and the positive effects on the functional health status of the elderly users [24] and overall quality of life has been seen [25].

\section{Predict the Usefulness of Hearing Aids}

Many variables have been investigated as predictors of the success of hearing aids. In this research, the effects of internal factors (individual characteristics, hearing loss, auditory processing status, personality, etc.) and external factors (hearing aids, audiologists, and counseling, etc.) on the usefulness of hearing aids will be reviewed.

\section{Personal Characteristics}

Aging is associated with a reduction in the abilities and experiencing more diseases. Generally, as age increases, the performance of the person with hearing aids decreases [26, 27]. According to many studies, there is no association between the patient's age and the rate of reception, use of, and satisfaction with hearing aids [2838]. On the other hand, Mulrow et al. and Hosford, in two separate studies, concluded that young people report more satisfaction with hearing aids [39, 40], but in second by Hosford, no correlation with degree of hearing aid use was seen [39].

According to Humphrey et al. [33], patients who experience hearing problems before reaching the retirement age (65 years) are more likely to seek treatment than other patients who have started their problems at an older age. However, the age of hearing loss onset does not affect hearing aids reception and use by patients[41]

In Homes et al. (2003), the gender difference was effective in hearing aids. In this study, the CPHI index was used, and the probability of accepting communication problems, the use of non-verbal strategies to compensate for difficult communication situations, anger, fatigue, and negative emotions was more in women in comparison to men [41]. This finding is similar to Erlers' report that gender can affect the efficacy of hearing aids [23]. However, reports on the lack of gender impact on this issue are more [6, 26, 29-35, 37, 38, 42-44]. So, in general, gender does not affect the usefulness of hearing aids. 


\section{Patient's Auditory Performance}

Patients with severe hearing impairments often use their hearing aids $[45,46]$. The better the hearing threshold, the better the person's performance with the hearing aid [47]. Reports differ in the relationship between auditory thresholds and the benefits of hearing aids. Some find this relationship strong [48], while others did not see strong relationships [49]. Hearing loss (average net tone thresholds) seems to be associated with a lot of patient's referral followed by hearing aids, so the hearing threshold increases the chance of receiving hearing aids $[23,31,33,37,42,44,50]$.

However, hearing loss alone does not affect the satisfaction and the amount of hearing aids. However, in three other studies, there is a correlation between hearing thresholds with hearing aid use [30], satisfaction rates [38] and the rate of use and satisfaction [39], and, people with hearing loss are more satisfied with hearing aids and use them more. The amount of hearing loss experienced by a person has a positive correlation with the amount of hearing aids use, and there is a correlation between the person's report of the hearing problem and the rate of hearing aids use. However, the lack of relationship between hearing loss (pure-tone-average) and satisfaction and hearing aids has also been reported, suggesting that hearing loss alone may not be a good predictor of the usefulness of hearing aids [51, 52].

\section{Auditory Processing Capabilities}

Auditory abnormalities in the user can have adverse effects on the usefulness of hearing aids [53-55]. Frequency resolution is one of the factors that play an essential role in determining the person's benefit from hearing aids. Other central processing, such as co-modulation masking release, also plays an important role [53, 54]. Weakness in central auditory processing results in poor performance with hearing aids decreased satisfaction in the elderly, and poor prognosis of using hearing aids in this group [55]. However, the use of phonological balancing tests and combinatorial identification tests have shown no correlation between central auditory performance with the benefit of hearing aids [56].

\section{Non-auditory Abilities}

In older people, various general diseases, reduced movement, and social isolation can reduce the success of hearing aids [57-59]. Patients with better manual abilities use more of their hearing aids $[41,60]$ and generally are more satisfied [61]. In these studies, the audiologist determines the skill level of the individual.

Reducing cognitive and functional abilities can limit the use of hearing aids [6]. Some patients also mentioned the lack of hearing aid and the complexity of its application as factors in not using hearing aids. Individual cognitive abilities are effective in using hearing aids [62]. The result of this study is in line with the theory of the possibility of increasing cognitive abilities following the use of hearing aids [63]. However, the relationship between these factors and the rate of depression and social isolation has not been determined yet.

\section{Personality and Motivation of the Patient}

The character is a general term and involves various aspects. Each study examines one or more aspects of the character to determine which personality traits are effective in receiving, using, and satisfying with the hearing aids. The less a person's depression score, the more satisfaction and use of hearing aids would be [30]. Among those who refer to using hearing aids, the tendency to higher pragmatism and less nervousness have been observed [64]. However, this study failed to identify personality traits for predicting the use and satisfaction of hearing aids in the next stage follow up. The level of self-confidence is effective in satisfaction [51].

One of the factors that has been studied about the use of and satisfaction with hearing aids is the issue of patient's motivation. There is a positive relationship between being motivated by others andhearing aids use, and, the patient's behavior depends on the degree of social pressure that applies from the most important others $[42,65]$. This does not affect the use of hearing aids $[32,43]$. There are different results about degree of satisfaction with hearing aids. In Wilson and Stephen's review study, the source of the patients' motivation does not affect their satisfaction, while there is a report of the association between these two factors. Also, patients who receive more support from their family and other important people will be more successful in using hearing aids [60].

\section{Patient's Attitude}

In the case of receiving a hearing aid, the positive impact of the individual's attitude towards hearing aids has been observed [44, 60, 66]. Hickson divided his patients into four groups based on attitude in the first meeting in the clinic: group one with a completely positive attitude to group four who had given the hearing aids. Group 
one and two kept using hearing aids, but the use of group three was occasional or did not use their hearing aids at all $[32,43]$. However, his subsequent review showed that this factor did not affect the patient's satisfaction [32]. Wilson and Stephen reported a higher level of satisfaction and cooperation with the rehabilitation process in people with a positive attitude towards hearing aids in the receiving period [61]. There is also a positive relationship between this factor and the use of and satisfaction with hearing aids [30]. This result is in contradiction with the results of two other studies that have not seen such a relationship [29, 34]. Brooks and Halam used the HARQ questionnaire and suggested the possible cause of this finding before hearing aids [29].

Regarding the patients' attitude toward hearing loss, if they accept their hearing problems before receiving the hearing aid, they are more likely to use these aids [34]. There were higher acceptance and less stress on auditory problems in a group of patients who had received hearing aids [41]. A study was conducted on the personality of the patients who had attended in audiology clinics to receive hearing aids. According to Cox et al., patients referring to hearing aids compared with a random group of people in the community are not different, and there is a common ground between them. Their review was done by a questionnaire that examined individual personality traits. In general, patients who referred for hearing aids respond to life challenges more, and use social support strategies less [64].

\section{Experienced Disability}

Many studies investigated the patients' reports on the extent of their work limitations due to hearing loss. Interestingly, in all studies conducted in this area, the results of positive correlations have been reported in all sectors of the study of the provision, use of, satisfaction with, and benefits of hearing aids [31, 37-42, 44, 50, 65, 67]. This means that the more the hearing problem reported by the patient, the amount of referral to the hearing aid, the amount of its use, and ultimately the satisfaction with it would be higher.

\section{Expectations}

Several studies investigated the relationship of pre-prescribing expectations with the use of and satisfaction with hearing aids. The person's expectations before the fitting are considered as a factor in the prediction of the usefulness of the hearing aid [65]. According to these studies, the relationship between pre-prescribing expectations with the use of and satisfaction with hearing aids is positive, which means that the higher the expectations, the more would be the use and satisfaction. However, for some of the patients, the expectations will largely depend on the personality [53, 64, 68]. And, in some studies, the relationship between these factors has not been reported [30, 34, 51, 69].

\section{Hearing aid History}

One of the possible factors influencing the use and satisfaction of patients is the issue of their previous hearing experience. The higher the experience of the patient in using the hearing aids, his or her satisfaction with using hearing aids would be higher [38, 39].

\section{Duration of Use During the Day}

Two factors contribute to the success of using hearing aids. The first, the intervention should make a favorable change in the patient's condition, and secondly, the patient must agree to the intervention program to benefit from it [70]. There are certainly several tools available to determine whether the hearing aid is used and whether the patient has experienced a change in speech comprehension or quality of life. The length of use of the hearing aid has a positive relationship with the benefits of hearing aids (that is, improving speech comprehension) and patient's satisfaction $[38,71]$. Homes, for example, used a hearing aid as a distinct dimension and relatively independent of the utility of hearing aids [72].

One of the problems of researchers is how to assess the amount of using hearing aids. Individual reports are criticized because they depend on the patient's responses that may be vague and exaggerated $[73,74]$. On the other hand, if the patient forgets to turn off the hearing aids when not in use, objective assessments (data log and battery consumption) will also yield errors [70]. It would seem better to have a combination of these two evaluations [70, 75]. Some believe that the use of more than four hours of hearing aids throughout the day is an indicator of the success of hearing aids [48]. However, some patients with limited and specific hearing needs can be successful users, although their using time is very short [34].

\section{Hearing Aid Features}

Regarding the characteristics of hearing aids, biorhythm enhancement, and advanced processing technologies can enhance the success of hearing aids and lead to more prolonged use [76]. The type of hearing aid can also be effective in its usefulness. Ihler et al. [77] study was conducted in patients who could not use conventional hearing aids and received ear implanted 
hearing aids. These hearing aids have provided speech recognition as well as a higher quality of life. Beneficiaries of hearing aids report a higher degree of satisfaction and more benefits. Also, according to this research, there is a difference between men and women in some items. In other words, women have earned higher points in the "impact on others" item in the IOI-HA questionnaire [52].

Some of the patients often have reported that the reasons for failure in hearing aid use were noise, feedback, and whistle, and lower degree of cost-benefit [7]. These people may not be candidates for hearing aid assessments. Frequency transfer is one of the tools available in digital hearing aids. The impact of this type of processing on the benefits of hearing aids has been studied. McCreery et al. provided some evidence on the effectiveness of this approach but concluded that more research is still needed in this area [78].

In cases where there is a 1-way hearing loss, hearing aids can be crossed. In one study, the possibility of comparing conventional hearing aids, Bone Anchored Hearing Aid (BAHA), and trans-cranial transplants for 10 patients with 1-way loss was provided. Their results indicated that most of them had chosen the BAHA type [79].

\section{The Role of Counseling and Audiologist}

Consultation is effective not only in the receiving phase but also in the amount of motivation for continuous use of hearing aids. Patient-centered approaches, with objective assessments of the use of hearing aids in target situations, can be useful in designing and following the rehabilitation program for patients [70]. Determining whether a hearing aid is regularly used and effective is an essential part of the hearing aid evaluation. It is recommended that regular follow-up meetings be held to improve the usefulness of hearing aids, especially for adults whose social isolation may worsen in the absence of hearing aids $[75,80]$.

The effect of counseling has been reported to patients with a history of hearing aids [81]. Patients between the two hearing aids with similar acoustic features reported differences in the quality of the sound because they were told at a consultation that these hearing aids are different. Of course, patients who recently received hearing aids did not show such an effect. They find that the probable cause of this finding in this group of patients is the habitual pattern of hearing aids that lessens the effect of placebo.

Table 1. Factors affecting the use of and satisfaction with the hearing aids in two steps before and after receiving it

\begin{tabular}{ccc}
\hline Factor & Stage Before Receiving & Stage After Receiving \\
\hline Individual features (age-gender) & + & - \\
Auditory condition & - & + \\
Auditory processing & + & + \\
\hline Non-auditory abilities (hand abilities, cognitive functional) & + & + \\
Personality and motivation of the patient & + & + \\
Patient's attitude (about hearing aids) & - & + \\
Experienced handicap & - & + \\
Expectations & + & + \\
History of hearing aid use & + & + \\
Duration of use during the day & + \\
Hearing aid features & +
\end{tabular}

A positive sign indicates the effect of that factor at that stage, and the negative sign indicates that the factor lacks any impact 
It seems that counseling $[51,82]$, and motivational interviewing techniques [83] not only improve the amount of hearing aids uptake but also motivate its continuous use. Patient-centered personalized approaches and objective assessments of hearing aids in target situations can be useful in designing and monitoring rehabilitation programs for patients receiving a hearing aid [70]. In general, the role of counseling on the use of and satisfaction with hearing aids is still unclear. Although some short-term effects have been observed [84], it is crucial to examine how these effects remain in the long run [32, $85,86]$. In these studies, different methods of counseling and interventions were used. For example, in the study of Ericsson and colleagues, when the patient was given more structured guidance, the use of hearing aids was higher, and the level of satisfaction with the use of hearing aids and the sound quality were also higher [87].

\section{Conclusion}

Patients with hearing impairment have a wide range of problems and needs. One of the hallmarks of hearing aids in prescribing and helping patients is to solve their problems and anticipate the appropriate treatment plan. It is not easy to convince a patient to get a hearing aid when its level of performance is not determined yet. The therapist should be able to determine some of the possible benefits and disadvantages of hearing aids for each patient, and the final decision is with the patient. In this paper, we tried to examine the various studies with a general view of the factors involved in this topic.

In general, these factors can be classified into two broad categories, the factors before obtaining the hearing aid that persuades the patient to provide it, and after receiving the hearing aid, which makes the patient use it and satisfy with it. Table 1 summarizes these factors.

You should pay attention to the patient's age. In the elderly, we usually experience reduced manual abilities and slower mental functioning, such as hearing and cognitive processes. So when we consider age as an independent variable, we should also note that part of the patient's problems with hearing aids is due to the changes in other abilities, not just age. In the study of Hosford, which was mentioned in the individual widgets section, the relationship between age and patient's satisfaction is indicated by the SADL (Satisfaction with Amplification in Daily Life) questionnaire.

In this research, abilities such as cognitive and auditory processing, and so on have not been evaluated individually, while studies have shown that non-alcoholic abilities are useful in the post-hearing phase of the hearing aid and can affect the patient's use and satisfaction. Hence, it could be one of the weaknesses of their study.

The patient's audiology profile is another factor that has been studied. The patient with a worse hearing threshold is more likely aware of his or her hearing problem, resulting in a higher chance of receiving hearing aids. But in general, it cannot be considered a definitive indicator for predicting the usefulness of hearing aids in the postreceiving phase. Each patient has unique listening needs that depend on his or her lifestyle, career and social relationships. Thus, you cannot just consider the threshold of hearing loss for the future use of hearing aids. In contrast to factors such as the state of hearing, the degree of disability experienced by the patient, his or her expectations of hearing aids, the characteristics of hearing aids, the length of use, the advice of the surgeon, and so on, can bring our prediction of the ultimate benefit of the patient closer to reality. The audiologist should review all of these aspects with a general view of the patient's condition and explain them to the patient.

\section{Ethical Considerations}

\section{Compliance with ethical guidelines}

This article does not contain any studies involving human and animals' participants performed by any of the authors.

\section{Funding}

This research did not receive any specific grant from funding agencies in the public, commercial, or not-forprofit sectors.

\section{Authors contributions}

Data collection, conceptualization, investigation, and supervision: Mahsa Hamidi Pouyandeh, Reza Hoseinabadi; Writing and original draft preparation: Mahsa Hamidi Pouyandeh; Writing, review \& editing, and visualization: Reza Hoseinabadi.

\section{Conflict of interest}

The authors declared no conflict of interest. 


\section{References:}

[1] Popelka MM, Cruickshanks KJ, Wiley TL, Tweed TS, Klein BE Klein R. Low prevalence of hearing aid use among older adults with hearing loss: The epidemiology of hearing loss study. Journal of the American Geriatrics Society. 1998; 46(9):1075-8. [DOI:10.1111/j.1532-5415.1998.tb06643.x] [PMID]

[2] Smeeth L, Fletcher AE, Ng ES-W, Stirling S, Nunes M Breeze E, et al. Reduced hearing, ownership, and use of hearing aids in elderly people in the UK-the MRC Trial of the assessment and management of older people in the community: A cross-sectional survey. The Lancet. 2002; 359(9316):1466-70. [DOI:10.1016/S0140-6736(02)08433-7]

[3] Smits C, Kramer SE, Houtgast T. Speech reception thresholds in noise and self-reported hearing disability in a general adult population. Ear and Hearing. 2006; 27(5):538-49. [DOI:10.1097/01.aud.0000233917.72551.cf] [PMID]

[4] Dillon H, Birtles G, Lovegrove R. Measuring the outcomes of a national rehabilitation program: Normative data for the client oriented scale. Journal of the American Academy of Audiology. 1999; 10(2):67-79.

[5] Hickson L, Worrall L. Beyond hearing aid fitting: Improving communication for older adults. International Journal of Audiology. 2003; 42(sup2):84-91. [DOI:10.3109/14992020309074649]

[6] Lupsakko TA, Kautiainen HJ, Sulkava R. The non-use of hearing aids in people aged 75 years and over in the city of Kuopio in Finland. European Archives of Oto-Rhino-Laryngology and Head \& Neck. 2005; 262(3):165-9. [DOI:10.1007/ s00405-004-0789-x] [PMID]

[7] Kochkin S. Marke Trak VII: Obstacles to adult non $\square$ user adoption of hearing aids. The Hearing Journal. 2007; 60(4):2451. [DOI:10.1097/01.HJ.0000285745.08599.7f]

[8] Vestergaard Knudsen L, Öberg M, Nielsen C, Naylor G, Kramer SE. Factors influencing help seeking, hearing aid uptake, hearing aid use and satisfaction with hearing aids: A review of the literature. Trends in Amplification. 2010; 14(3):12754. [DOI:10.1177/1084713810385712] [PMID] [PMCID]

[9] Brooks D. Measures for the assessment of hearing aid provision and rehabilitation. British Journal of Audiology. 1990; 24(4):229-33. [DOI:10.3109/03005369009076561] [PMID]

[10] Humes LE, Christensen L, Thomas T, Bess FH, HedleyWilliams A, Bentler R. A comparison of the aided performance and benefit provided by a linear and a two-channel wide dynamic range compression hearing aid. Journal of Speech, Language, and Hearing Research. 1999; 42(1):65-79. [DOI:10.1044/jslhr.4201.65] [PMID]

[11] Levitt H, Resnick S. Speech reception by the hearing-impaired: Methods of testing and the development of new tests. Scandinavian Audiology Supplementum. 1978; 6:107-30. [PMID]

[12] Mueller HG, Hawkins DB, Northern JL. Probe microphone measurements: Hearing aid selection and assessment. San Diego: Singular Publishing Group; 1992.

[13] Wetzell C, Harford ER. Predictability of real ear hearing aid performance from coupler measurements. Ear and Hearing. 1983; 4(5):237-42. [DOI:10.1097/00003446-198309000-00003] [PMID]
[14] Arlinger S, Billermark E. One year follow-up of users of a digital hearing aid. British Journal of Audiology. 1999; 33(4):223-32. [DOI:10.3109/03005369909090103] [PMID]

[15] Jenstad LM, Seewald RC, Cornelisse LE, Shantz J. Comparison of linear gain and wide dynamic range compression hearing aid circuits: Aided speech perception measures. Ear and Hearing. 1999; 20(2):117-26. [DOI:10.1097/00003446199904000-00003] [PMID]

[16] Weinstein BE. The quantification of hearing aid benefit in the elderly: The role of self-assessment measures. Acta Oto-Laryngologica. 1991; 111(sup476):257-61. [DOI:10.3109/00016489109127287] [PMID]

[17] Tye-Murray N. Foundations of aural rehabilitation: Children, adults, and their family members. Boston, Massachusetts: Cengage Learning; 2005.

[18] Cox RM, Gilmore C, Alexander G. Comparison of two questionnaires for patient-assessed hearing aid benefit. Journal of the American Academy of Audiology. 1991; 2(3):134-45. [PMID]

[19] Ventry IM, Weinstein BE. The hearing handicap inventory for the elderly: A new tool. Ear and Hearing. 1982; 3(3):128-34 [DOI:10.1097/00003446-198205000-00006] [PMID]

[20] Humes LE. Dimensions of hearing aid outcome. Journal of the American Academy of Audiology. 1999; 10(1):26-39. [PMID]

[21] Mulrow CD, Aguilar C, Endicott JE, Tuley MR, Velez R, Charlip WS, et al. Quality-of-life changes and hearing impairment. Annals of Internal Medicine. 1990; 113(3):188-94 [DOI:10.7326/0003-4819-113-3-188] [PMID]

[22] Bridges JA, Bentler RA. Relating hearing aid use to well-being among older adults. The Hearing Journal. 1998; 51(7):39 42. [DOI:10.1097/00025572-199807000-00002]

[23] Garstecki DC, Erler SF. Hearing loss, control, and demographic factors influencing hearing aid use among older adults. Journal of Speech, Language, and Hearing Research. 1998; 41(3):527-37. [DOI:10.1044/jslhr.4103.527] [PMID]

[24] Crandell CC. Hearing aids: Their effects on functional health status. The Hearing Journal. 1998; 51(2):22-4. [DOI:10.1097/00025572-199802000-00002]

[25] Kochkin S. Marke Trak V:" Why my hearing aids are in the drawer": The consumers' perspective. The Hearing Journal. 2000; 53(2):34-6. [DOI:10.1097/00025572-200002000-00004]

[26] Crowley HJ, Nabelek IV. Estimation of client-assessed hearing aid performance based upon unaided variables. Journal of Speech, Language, and Hearing Research. 1996; 39(1):19-27. [DOI:10.1044/jshr.3901.19] [PMID]

[27] Jerram JCK, Purdy SC. Evaluation of hearing aid benefit using the shortened hearing aid performance inventory. JournalAmerican Academy of Audiology. 1997; 8(1):18-26. [PMID]

[28] Bentler RA, Niebuhr DP, Getta JP, Anderson CV. Longitudinal study of hearing aid effectiveness. II: Subjective measures. Journal of Speech, Language, and Hearing Research. 1993; 36(4):820-31. [DOI:10.1044/jshr.3604.820] [PMID]

[29] Brooks D, Hallam R. Attitude to hearing difficulty and hearing aids and the outcome of audiological rehabilitation. British Journal of Audiology. 1998; 32(4):217-26. [DOI:10.3109/03005364000000069] [PMID] 
[30] Gatehouse S. Components and determinants of hearing aid benefit. Ear and Hearing. 1994; 15(1):30-49. [DOI:10.1097/00003446-199402000-00005] [PMID]

[31] Gussekloo J, De Bont L, Von Faber M, Eekhof J, De Laat J, Hulshof J, et al. Auditory rehabilitation of older people from the general population-the Leiden 85-plus study. British Journal of General Practice. 2003;53(492):536-40. [PMID] [PMCID]

[32] Hickson L, Timm M, Worrall L, Bishop K. Hearing aid fitting: Outcome for older adults. Australian Journal of Audiology. 1999; 21(1):9-21.

[33] Humphrey C, Herbst KG, Faurqi S. Some characteristics of the hearing-impaired elderly who do not present themselves for rehabilitation. British Journal of Audiology. 1981; 15(1):2530. [DOI:10.3109/03005368109108950] [PMID]

[34] Jerram J, Purdy SC. Technology, expectations, and adjustment to hearing loss: Predictors of hearing aid outcome. JournalAmerican Academy of Audiology. 2001; 12(2):64-79. [PMID]

[35] Norman M, George CR, McCarthy D. The effect of pre-fitting counselling on the outcome of hearing aid fittings. Scandinavian audiology. 1994; 23(4):257-63. [DOI:10.3109/01050399409047517] [PMID]

[36] Chang WH, Tseng HC, Chao TK, Hsu CJ, Liu TC. Measurement of hearing aid outcome in the elderly: Comparison between young and old elderly. Otolaryngology-Head and Neck Surgery. 2008; 138(6):730-4. [DOI:10.1016/j. otohns.2008.02.012] [PMID]

[37] Helvik AS, Wennberg S, Jacobsen G, Hallberg LRM. Why do some individuals with objectively verified hearing loss reject hearing aids? Audiological Medicine. 2008; 6(2):141-8. [DOI:10.1080/16513860802178692]

[38] Uriarte M, Denzin L, Dunstan A, Sellars J, Hickson L. Measuring hearing aid outcomes using the Satisfaction with Amplification in Daily Life (SADL) questionnaire: Australian data. Journal of the American Academy of Audiology. 2005; 16(6):383-402. [DOI:10.3766/jaaa.16.6.6] [PMID]

[39] Hosford-Dunn H, Halpern J. Clinical application of the SADL scale in private practice II: Predictive validity of fitting variables. Journal of the American Academy of Audiology. 2001; 12(1):15-36. [PMID]

[40] Mulrow CD, Tuley MR, Aguilar C. Correlates of successful hearing aid use in older adults. Ear and Hearing. 1992; 13(2):10813. [DOI:10.1097/00003446-199204000-00007] [PMID]

[41] Humes LE, Wilson DL, Humes AC. Examination of differences between successful and unsuccessful elderly hearing aid candidates matched for age, hearing loss and gender: Evaluation of the differences between successful and unsuccessful candidates of older age, to the use of hearing aid by age, degree of hearing loss and sex. International Journal of Audiology. 2003; 42(7):43241. [DOI:10.3109/14992020309080053] [PMID]

[42] Duijvestijn J, Anteunis LJ, Hoek C, Van Den Brink RH Chenault MN, Manni JJ. Help-seeking behaviour of hearingimpaired persons aged $\geq 55$ years: Effect of complaints, significant others and hearing aid image. Acta Oto-Laryngologica. 2003; 123(7):846-50. [DOI:10.1080/0001648031000719] [PMID]

[43] Hickson L, Hamilton L, Orange SP. Factors associated with hearing aid use. Australian Journal of Audiology. 1986; 8(2):37-41.
[44] Van den Brink R, Wit H, Kempen G, Van Heuvelen M. Attitude and help-seeking for hearing impairment. British Journal of Audiology. 1996; 30(5):313-24. [DOI:10.3109/03005369609076779] [PMID]

[45] Brooks D. Factors relating to the under-use of postaural hearing aids. British Journal of Audiology. 1985; 19(3):211-7. [DOI:10.3109/03005368509078975] [PMID]

[46] Satherly NA. A survey of hearing aid users and the establishment of a hearing aid rehabilitation program in the Christchurch region [MSc. thesis]. New Zealand: University of Canterbury; 1992.

[47] Purdy SC, Jerram JCK. Investigation of the profile of hearing aid performance in experienced hearing aid users. Ear and Hearing. 1998; 19(6):473-80. [DOI:10.1097/00003446199812000-00008] [PMID]

[48] Kochkin S. MarkeTrak IV Norms: Subjective measures of satisfaction and benefit. Dallas, Texas: American Academy of Audiology Convention; 1995.

[49] Schum DJ. Responses of elderly hearing aid users on the hearing aid performance inventory. Journal of the American Academy of Audiology. 1992; 3(5):308-14. [PMID]

[50] Swan I, Gatehouse S. Factors influencing consultation for management of hearing disability. British Journal of Audiology. 1990; 24(3):155-60. [DOI:10.3109/03005369009076550] [PMID]

[51] Ferguson MA, Woolley A, Munro KJ. The impact of self-efficacy, expectations, and readiness on hearing aid outcomes. International Journal of Audiology. 2016; 55(sup3):S34-41. [D OI:10.1080/14992027.2016.1177214] [PMID]

[52] Arlinger S, Nordqvist P, Öberg M. International outcome inventory for hearing aids: Data from a large Swedish quality register database. American Journal of Audiology. 2017; 26(3S):443-50. [DOI:10.1044/2017_AJA-16-0123] [PMID]

[53] Gatehouse S. Factors that influence the benefit from amplification in the elderly. Acta Oto-laryngologica. 1991; 111(sup476):262-9. [DOI:10.3109/00016489109127288] [PMID]

[54] Gatehouse S. The role of non-auditory factors in measured and self-reported disability. Acta Oto-Laryngologica. 1991; 111(Suppl. 476):249-56. [DOI:10.3109/00016489109127286]

[55] Stach BA, Loiselle LH, Jerger JF. Special hearing aid considerations in elderly patients with auditory processing disorders. Ear and Hearing. 1991; 12(6):131S-8S. [DOI:10.1097/00003446-199112001-00007] [PMID]

[56] Kricoa PB, Laaner SA, Sandridge SA, Yanke RB. Perceived benefits of amplification as a function of central auditory status in the elderly. Ear and Hearing. 1987; 8(6):337-42. [DOI:10.1097/00003446-198712000-00009] [PMID]

[57] Cohn ES. Hearing loss with aging: Presbycusis. Clinics in Geriatric Medicine. 1999; 15(1):145-61. [DOI:10.1016/S07490690(18)30079-X]

[58] Evenhuis HM. Medical aspects of ageing in a population with intellectual disability: I. Visual impairment. Journal of Intellectual Disability Research. 1995; 39(1):19-25. [DOI:10.1111/j.1365-2788.1995.tb00909.x] [PMID]

[59] Welzl-Müller K, Stephan K. The benefit of hearing aids: Influence of hearing loss and age. Scandinavian Audiology. 1986; 15(2):115-9. [DOI:10.3109/01050398609045962] [PMID] 
[60] Hickson L, Meyer C, Lovelock K, Lampert M, Khan A. Factors associated with success with hearing aids in older adults. International Journal of Audiology. 2014; 53(Suppl. 1):S18S27. [DOI:10.3109/14992027.2013.860488] [PMID]

[61] Wilson C, Stephens D. Reasons for referral and attitudes toward hearing aids: Do they affect outcome? Clinical Otolaryngology. 2003; 28(2):81-4. [DOI:10.1046/j.13652273.2003.00669.x] [PMID]

[62] Dawes P, Cruickshanks KJ, Fischer ME, Klein BE, Klein $\mathrm{R}$, Nondahl DM. Hearing-aid use and long-term health outcomes: Hearing handicap, mental health, social engagement, cognitive function, physical health, and mortality. International Journal of Audiology. 2015; 54(11):838-44. [DOI:10.3109 /14992027.2015.1059503] [PMID] [PMCID]

[63] Acar B, Yurekli MF, Babademez MA, Karabulut H, Karasen RM. Effects of hearing aids on cognitive functions and depressive signs in elderly people. Archives of Gerontology and Geriatrics. 2011; 52(3):250-2. [DOI:10.1016/j.archh ger.2010.04.013] [PMID]

[64] Cox RM, Alexander GC, Gray GA. Who wants a hearing aid? Personality profiles of hearing aid seekers. Ear and Hearing. 2005; 26(1):12-26. [DOI:10.1097/00003446200502000-00002]

[65] Pronk M, Deeg DJ, Versfeld NJ, Heymans MW, Naylor G, Kramer SE. Predictors of entering a hearing aid evaluation period: A prospective study in older hearing-help seekers. Trends in Hearing. 2017; 21:2331216517744915. [DOI:10.1177/2331216517744915] [PMID] [PMCID]

[66] Takahashi G, Martinez CD, Beamer S, Bridges J, Noffsinger $\mathrm{D}$, Sugiura $\mathrm{K}$, et al. Subjective measures of hearing aid benefit and satisfaction in the NIDCD/VA follow-up study. Journal of the American Academy of Audiology. 2007; 18(4):323-49. [DOI:10.3766/jaaa.18.4.6] [PMID]

[67] Saunders GH, Cienkowski KM. Refinement and psychometric evaluation of the attitudes toward loss of hearing questionnaire. Ear and Hearing. 1996; 17(6):505-19. [DOI:10.1097/00003446-199612000-00006] [PMID]

[68] Wong L, Hickson L, McPherson B. Hearing aid expectations among Chinese first-time users: Relationships to postfitting satisfaction. Australian and New Zealand Journal of Audiology. 2004; 26(1):53. [DOI:10.1375/audi.26.1.53.55986]

[69] Saunders GH, Jutai JW. Hearing specific and generic measures of the psychosocial impact of hearing aids. Journal of the American Academy of Audiology. 2004; 15(3):238-48 [DOI:10.3766/jaaa.15.3.6] [PMID]

[70] Perez E, Edmonds BA. A systematic review of studies measuring and reporting hearing aid usage in older adults since 1999: A descriptive summary of measurement tools. PLoS One. 2012; 7(3):e31831. [DOI:10.1371/journal.pone.0031831] [PMID] [PMCID]

[71] Roup CM, Noe CM. Hearing aid outcomes for listeners with high-frequency hearing loss. American Journal of Audiology. 2009; 18(1):45-52. [DOI:10.1044/1059-0889(2009/08-0028)]

[72] Humes LE, Garner CB, Wilson DL, Barlow NN. Hearing-aid outcome measures following one month of hearing aid use by the elderly. Journal of Speech, Language, and Hearing Research. 2001; 44(3):469-86. [DOI:10.1044/1092-4388(2001/037)]
[73] Humes LE, Halling D, Coughlin M. Reliability and stability of various hearing-aid outcome measures in a group of elderly hearing-aid wearers. Journal of Speech, Language, and Hearing Research. 1996; 39(5):923-35. [DOI:10.1044/ jshr.3905.923] [PMID]

[74] Taubman LB, Palmer CV, Durrant JD, Pratt S. Accuracy of hearing aid use time as reported by experienced hearing aid wearers. Ear and Hearing. 1999; 20(4):299-305. [DOI:10.1097/00003446-199908000-00003] [PMID]

[75] Brooks DN. The time course of adaptation to hearing aid use. British Journal of Audiology. 1996; 30(1):55-62. [DOI:10.3109/03005369609077930] [PMID]

[76] Bertoli S, Staehelin K, Zemp E, Schindler C, Bodmer D, Probst R. Survey on hearing aid use and satisfaction in Switzerland and their determinants. International Journal of Audiology. 2009; 48(4):183-95. [DOI:10.1080/14992020802572627] [PMID]

[77] Ihler F, Bewarder J, Blum J, Matthias C, Canis M. Longterm functional outcome and satisfaction of patients with an active middle ear implant for sensorineural hearing loss compared to a matched population with conventional hearing aids. European Archives of Oto-Rhino-Laryngology. 2014; 271(12):3161-9. [DOI:10.1007/s00405-013-2811-7] [PMID]

[78] McCreery RW, Venediktov RA, Coleman JJ, Leech HM. An evidence-based systematic review of directional microphones and digital noise reduction hearing aids in school-age children with hearing loss. American journal of audiology. 2012; 21(2):295-312. [DOI:10.1044/1059-0889(2012/12-0014)]

[79] Hol MK, Kunst SJ, Snik AF, Cremers CW. Pilot study on the effectiveness of the conventional CROS, the transcranial CROS and the BAHA transcranial CROS in adults with unilateral inner ear deafness. European Archives of Oto-RhinoLaryngology. 2010; 267(6):889-96. [DOI:10.1007/s00405-0091147-9] [PMID] [PMCID]

[80] Goggins S, Day J. Pilot study: Efficacy of recalling adult hearing-aid users for reassessment after three years within a publiclyfunded audiology service. International Journal of Audiology. 2009; 48(4):204-10. [DOI:10.1080/14992020802575687] [PMID]

[81] Naylor G, Öberg M, Wänström G, Lunner T. Exploring the effects of the narrative embodied in the hearing aid fitting process on treatment outcomes. Ear and Hearing. 2015; 36(5):517-26. [DOI:10.1097/AUD.0000000000000157] [PMID]

[82] Vuorialho A, Karinen P, Sorri M. Effect of hearing aids on hearing disability and quality of life in the elderly: Effect of hearing aids (AA) on hearing impairment and the quality of life of the elderly. International Journal of Audiology. 2006 45(7):400-5. [DOI:10.1080/14992020600625007] [PMID]

[83] Beck DL, Harvey MA. Creating successful professionalpatient relationships. Audiology Today. 2009; 21(5):36-47.

[84] Kemker BE, Holmes AE. Analysis of prefitting versus postfitting hearing aid orientation using the Glasgow Hearing Aid Benefit Profile (GHABP). Journal of the American Academy of Audiology. 2004; 15(4):311-23. [DOI:10.3766/jaaa.15.4.5] [PMID]

[85] Öberg M. Approaches to audiological rehabilitation with hearing aids: Studies on pre-fitting strategies and assessment of outcomes [PhD. Dissertation]. Linköping: Linköping University Electronic Press; 2008. 
[86] Öberg M, Andersson G, Wänström G, Lunner T. The effects of a sound awareness pre-fitting intervention: A randomized controlled trial. Audiological Medicine. 2008; 6(2):129-40. [DOI:10.1080/16513860802042062]

[87] Eriksson-Mangold M, Ringdahl A, Björklund A, Wåhlin B. The Active Fitting (AF) programme of hearing aids: A psychological perspective. British Journal of Audiology. 1990; 24(4):277-85. [DOI:10.3109/03005369009076566] [PMID] 